\title{
Developing Teaching Materials in English for Biology Incorporating the KKNI-based Assignments at the Biology Department of the Universitas Negeri Medan
}

\author{
Martina Asiati Napitupulu ${ }^{1 *}$, Herkules ${ }^{2}$ Amrizal $^{3}$ \\ 1,2,3 Biology Department, FMIPA, Universitas Negeri Medan, Indonesia \\ *tinanapitupulu@unimed.ac.id
}

\begin{abstract}
This study aims to develop the teaching materials of English for Biology (a module) at Biology Department as a response to the difficulty of students to deal with the KKNI assignments at Department Biology Universitas Negeri Medan. The research and development design is used refers to the Cunningham's (Borg \& Gall, 2003) and consists of stages: 1) Studying relevant literatures; 2) Planning the proposed purpose; 3) Developing early stages for the teaching material (product); 4) Evaluating the early product; 5) Correcting the product based on the evaluated stage; 6) Field assessment towards the examined product. Qualitative and quantitative methods were used to deal with the data. The instrument used to determine the feasibility of the module is questionnaires, both for students and validators. The effectiveness of the module was tested using the pre-experiment design with a one-group pre and post-test model. There is an increased value of 21.09. The validation shows that the teaching material and design is considered "very" valid as the scores are 3.00 and 3.24 (respectively). The responses about the practicality of the module are considered as positive as the score is 3.07 and $76.92 \%$. The module is considerably good as teaching material and is effectively improving the students' achievements in examination.
\end{abstract}

Keywords: teaching materials, module, KKNI, student's achievement

\section{Introduction}

There are two situations when it comes to teach the subject of English for Biology at Biology Department Universitas Negeri Medan. Some of students are considered as the ESL (English as a second Language) or preferably are more confident as LEP (Limited English Proficiency) students. The department certainly is not ready as the lecturers are not prepared in pre-service university classes to do and have not encountered in the educational experiences. This will leave us many questions. What strategies meet the needs of students who have limited English? What learning strategies will the department need to foster in these students who have limited English? How do we assess their learning?

The subject of English for Biology is intended to give students more experience and access to English as it will improve the students capability to enhance the quality of their scientific papers and insight [1]. In addition, the more global view that a scientifically-literate public is the easier the country enhances its market position [2]. In relevance, the education reform in EFL Indonesia is beginning to target the foundational levels of learning such as 
primary education. But for those who were not included anymore in the government reform target, who are those attending the university level of English will certainly experience a difficult time. On the hand, lecturers must recognize and respond positively to student's diversity and encourage students to participate fully in learning.

When science education and English literacy development are the core elements in EFL pre-service teacher education [3] the class should have specialist teachers who can focus on science education using English as the Medium of Instruction (EMI). Meanwhile, the Biology department depends on those who have been abroad to teach this subject. The strategies to teach the subject must be addressed as the students' level of English must also be taken into consideration. They come at various stages of language development, they may have difficulties understanding some idioms, figures of speech, and words with multiple meanings. They may have difficulty with complex structures and abstract academic concepts [4]. Some students may understand more complex speech still require repetition. They have acquired a vocabulary of key words or phrases covering many common situations. They use English spontaneously and most of them have difficulty expressing all their thoughts due to restricted English-speaking ability. It is very rare to find students at any group have adequate language skills for most day to day communication.

Owing to the difficulty of deciding strategies that suit the variability of the students' level of English, to have teachings material that can fit to any stage of difficulty offers a solution. Several researchers have questioned about knowledge of the learners' field of study the ESP teacher needs to have to be able to select, adapt, simplify authentic texts and develop the manual that would meet the requirements of Biology, and then teach learners [5,6]. Another problem is that the lecturers having no similar technical background relatively close to the field of study. Some of them are struggling to comprehend materials they require the students to master. But since the target in this subject is to facilitate students with adequate scientific English in their biology education journey, a good module may deal with the problem of having no standardized teaching materials for this subject

The strategies may start from understanding the students need to attend in the class. The time-consuming activities of the curriculum must be the first priority to deal with. There are six types of assignments of the KKNI curriculum that have had the profound effects on the students' time allocation. When every subject is required to these compulsory types of assignments, it is urgently needed that the material teachings must fit to this time limitation scenario. One of the possible choices is developing module that suits the variety of students' English competences and time. The main aim of this module is to tackle the gap between students' deficient (second) language competencies and their capacities in science. Understanding the role of language in science, and become aware of difficulties the students are facing with language in science are also important matter to deal with. The module have lecturers work with case scenarios of classrooms with students that either do not speak the language, or have limited knowledge of it and will design lesson plans to work around these issues.

There are six areas of competences students are expected to learn in the subject of Bahasa Inggris Biology or English for Biology. The language used in the module is Indonesian as it is going to be easier for the students to study. Using English is considerably inefficient in term of time. Students with serious difficulty in English may find this is an impossible task to do.

The first concern about the students' capability of attending this class is the grammar. The part of speech indicates how the word functions in meaning as well as grammatically within the sentence. Every single word we use belongs to one of eight word groups or parts of 
speech (noun, pronoun, verb, adjective, adverb, preposition, conjunction, and interjection). The module offers recalling information about all the parts of speech as it is assumed that students must be aware about what they have missed in the past and try to catch up with the current topic the subject is being delivered.

This part is the most important part of the module. Attending the class of English is undeniable that students must have a certain level of grammar confidence. Grammar is important because it is the language that makes it possible for us to talk about language. Awareness and understanding that parts of speech can be divided into sub-classes, prepositions can be divided into prepositions of time, prepositions of place etc. nouns can be divided into proper nouns, common nouns, and concrete nouns should be something they are aware about. It is important for students to know that a word can sometimes be in more than one part of speech. For example, with the word increase. Increase can be a verb e.g. Prices increased and increase can also be a noun e.g. There was an increase in the quality of medicine. In response, the materials in this part are dealing with the ability to identify only some of the grammar, which are noun, verb, and adjective.

The second concern is that students are not familiar with affixes in English, making new words by adding all sorts of bits to the front and back of existing terms. Activities in this part of the module consist of producing sentences using affixes (adding the bits to the base or stem of a word). Students learn using affixes, suffix and prefix. The assignments for grammar and affixes topic will together be considered to be the Routine Task (Tugas Rutin), the first assignment in the KKNI curricula. Here, the students have to do the assignments for four weeks in a row and will be submitted every week.

A sentence in English language can be divided into various parts and this is important for students to master. Writing and reading competences are based on this skill. Each part of a sentence serves its relative purpose and has some specific characteristics. Most of the students have a lot of confusion about what so called clause and phrase. Teaching them with clear differences between the clause and phrase may help them to write and read more efficient. The assignment for this part is to practice using the concept of clause and phrase, producing sentences for both concepts and will be considered to be engineering idea (Rekayasa Ide) task.

The fourth topic is the active and passive voices in English. Since the students have had the idea about these types of sentence in Bahasa Indonesia, it is suggested that students know about the types of sentence found in the scientific text-book or journals. The use of active voice in English is preferable as it promotes simple and straight-forward writing. As such, most scientific journals encourage the use of the active over the passive voice [7]. Students must realize that a well-written scientific manuscript worthy of publication is the use of appropriate verb tenses in the different sections of the manuscript. The assignment in this part of the module is considered as Critical Book Report. Students will experience finding the types of sentence in most scientific papers.

Reading a scientific paper is requiring a large amount of class time. A dedicated course specific to reading the literature may not be available in normal undergraduate course or curriculum. Reading a single paper may take students a very long time that they do not have. The ability to read is actually a process for them to evaluate and gather information from the scientific literature. The module provides information how they can gather information through understanding what the paragraphs are. The topic sentence will be the most important part to learn as it gives students understanding how a paragraph is organized. The activity for this topic is considered as Critical Journal Review. Students learn how to extract information provided by several journals and will be able to identify topic sentences which in turn can be a valuable skill to deal with composing their essays. 
The studying activity 6 is the following stage to previous journal and other text books reading comprehension. Here, the module is helping students to learn the well-known steps of reading comprehension, the SQ4R. This method of reading textbooks is an excellent strategy for both understanding and remembering information. It allows students to actively engage with learning, by translating the text they are reading into their own words.

Using module is considered practical for both students as it focuses on student-centered learning activities and culminates in a project for students to demonstrate understanding. The KKNI curricula will work together with the idea that students are able to develop a project to illustrate what they have learned, such as mini dictionary. Since modules use active rather than passive learning experiences, students may be more engaged, understand real-world applications of the concepts and further develop higher-order cognitive abilities. The ability to create data and meet problem in the topic of English for Biology subject is promoted by conducting a mini research, the relationship between the SKHUN (the letter of National Examination) scores and the result of the mid semester examination.

Traditionally ESP courses were typically designed for intermediate or advanced adult learners but now many students can start to learn academic or vocational English at an earlier age and at a lower level of proficiency. Unimed is on the way of responding the increasing numbers of learners are taught in English medium schools using approaches such as CLIL (Content and Language Integrated Learning). This subject is taught using the KKNI curricula will provide solution to the gap between the students' level of English and the curricula of the Bahasa Inggris Biologi or English for Biology subject.

When students combines subject matter and English language teaching the combination is intended to apply what the students learn in their English classes to their main field of study. Being able to use the vocabulary and structures that they learn in a meaningful context reinforces what is taught and increases their motivation. The students' abilities in their subjectmatter fields, in turn, improve their ability to acquire English. Subject-matter knowledge gives them the context they need to understand the English of the classroom. In the ESP (English for specific purposes) class, students are shown how the subject-matter content is expressed in English. The teacher can make the most of the students' knowledge of the subject matter, thus helping them learn English faster.

\section{Research Method}

Literature research is used to collect information to develop this module by examining the use of it in teaching English for specific purpose, using literature to choose part of the scientific English for this specific need and the KKNI, and using literature to refer the cognitive competence as an empirical and theoretical relevance to the research being conducted. In order to produce a module as a teaching material the aim of the study is developed from the learning outcomes of English for Biology subject.

The initial module and the formative evaluation as an instrument were developed and both were evaluated. The results were then used as a base for improving the quality of the initial module and for indicating the improvement of the student's achievement. The proposed module consists of: introduction (cover, preface, content list, figure list, and table list); content design (mapping concept, material, assignments, conclusion and evaluation); and closure (references and biography). The module prototype was then submitted to validators, the English content and instructional design experts. 
The field test for the initial module was conducted in order to obtain responses from the future users of the module, they are students and the lecturers. The module was then evaluated and fixed based on the negative responses and suggestion given by the respondents. The second field test was conducted to follow up all the responses given by the respondents and the pre-test was administered to obtain the student's initial score. The post-test was used to obtain data about the change that students may experience after using the modul.

The module evaluation sheets are used by the validators to evaluate the prototype of the module and the responses were then examined. The questionnaires from both lecturers and students were used to collect data for the field test of the initial module. The pre-test and posttest were used to evaluate the student's achievement before and after the use of modul in the teaching and learning process.

Qualitative data (the validators' evaluation results) were analyzed to obtain the total average score of the validity aspect ( $\mathrm{Va}$ ) and all the learning strategy of the module. The result obtained is categorized into not valid $(0 \leq \mathrm{Va}<1)$, less valid $(1 \leq \mathrm{Va}<2)$, valid $(2 \leq \mathrm{Va}<3)$, very valid $(3 \leq \mathrm{Va}=4)$ (adapted from Hobri, 2009). The module needs to be revised when the value of $\mathrm{Va}$ is less valid and not valid. The process to obtain the $\mathrm{Va}$ is conducted several times until the result reach the value of valid.

The responses from lecturers and students were re-organized to obtain the value of response by calculating the numbers and convert it into five categories. If the value of responses $(\mathrm{R})$ if more than $80 \%$ then the module receives a positive response classically. The categories are: $\mathrm{R}<25$ (very negative), $25 \geq \mathrm{R}<44$ (negative), $44 \geq \mathrm{R}<63$ (ok), $63 \geq \mathrm{R}<81$ (positive), $81 \geq \mathrm{R}<100$ (very positive) (Adapted from Maimunah, 2016). The student's achievement provides data for the module effectiveness.

\section{Results and Discussion}

\section{The Validation of the Module}

The module was validated and there are three indicators of the material aspect/content of the module were examined. Each value was calculated and referred to the value of validity indicated. The indicators are all fallen into valid and very valid, which indicate that the module validity value is between the 2.89 to 3.14 and the average is 3.00 . The aspect of design was examined for three aspects, the size, cover, and content of the module.

Table 1. The Content Aspect of the Module

\begin{tabular}{rlcl}
\hline No & Indicator & Average & Category \\
\hline $\mathbf{1}$ & Content & 2.89 & Valid \\
$\mathbf{2}$ & Performance & 3.00 & Very valid \\
$\mathbf{3}$ & Language & 3.14 & Very valid \\
\multicolumn{2}{l}{ Score for the Content } & 3.00 & Very valid \\
\hline
\end{tabular}


Table 2. The Design Aspect of the Module

\begin{tabular}{rlcl}
\hline No & Indicator & Average & Category \\
\hline $\mathbf{1}$ & Size & 3.84 & Very valid \\
$\mathbf{2}$ & Cover & 2.89 & Valid \\
$\mathbf{3}$ & Content & 2.99 & Valid \\
Score for the Design & 3.20 & Very valid \\
\hline
\end{tabular}

These indicators fall into only two categories, valid and very valid (average value is 3.24). Each of the result is summarized in Table 1 and 2.

\section{The Practicality of the Module}

The responses from students were used to see the value of practicality of the module. There are 147 students involved in the activity and come from five groups of students who are attending the subject of English for Biology. The students were asked to respond the module and fill the questionnaire's sheets for the aspects of visual, eye catching, language, content, and usefulness. All aspects were responded positive as the percentage of each of them are also in the positive category (see Table 3).

Table 3. Student's Responses

\begin{tabular}{llccl}
\hline No & Aspect & Average & $\begin{array}{c}\text { Percentage } \\
(\%)\end{array}$ & Category \\
\hline $\mathbf{1}$ & Visual & 3.10 & 77.53 & Positive \\
$\mathbf{2}$ & Eye catching & 2.68 & 71.2 & Positive \\
$\mathbf{3}$ & Language & 2.98 & 79.11 & Positive \\
$\mathbf{4}$ & Content & 2.95 & 78.05 & Positive \\
$\mathbf{5}$ & Usefulness & 2.93 & 76.16 & Positive \\
\hline
\end{tabular}

\section{The Effectiveness of the Module}

The average scores of students' multiple choices questions were calculated and the Figure 3 shows the differences among the results. There were 100 multiple choices questions for the topic of Parts of speech and vocabulary and 20 for the Reading comprehension. The lowest and highest score were 26 and 80 respectively with the average score is 55.35 (stand.dev $=13.528)$. The results show that the Chi-squared count $(14.558)<$ the Chi-squared table (15.50), the sample is homogeneous and normally distributed. The number of students who were included for the test was 46 from two groups only as some of them were declared as having no competence in English at all. These students were taken as samples and were considered to have confidence to take the test (Table 4).

The post-test result shows that the lowest and highest scores were 46 and 100 respectively with the average score is 76.44 . $(\mathrm{sd}=13.417)$, the increased average value is 21.09 (Figure 1). 
Table 4. The Description of the pre and post-test.

\begin{tabular}{ccccccc} 
& N & Min & Max & Mean & $\begin{array}{c}\text { Std. } \\
\text { Dev. }\end{array}$ & $\begin{array}{c}\text { Std. Error } \\
\text { Mean }\end{array}$ \\
\hline Pretest & 43 & 26 & 80 & 55.35 & 13.528 & 2.063 \\
Posttest & 43 & 46 & 100 & 76.44 & 13.417 & 2.046 \\
$\begin{array}{c}\text { Valid N } \\
\text { (leastwise) }\end{array}$ & 43 & & & & & \\
\hline
\end{tabular}

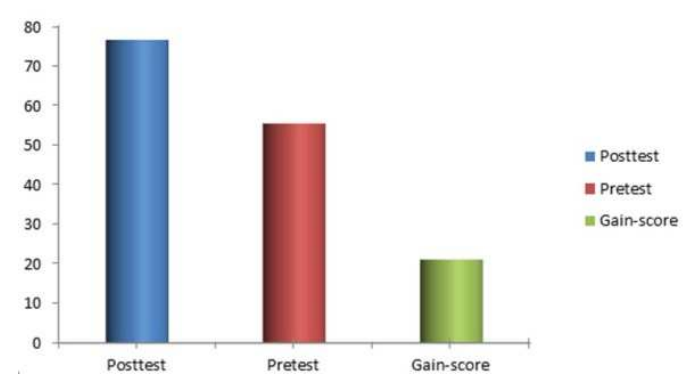

Fig.1. Mean score before and after applying developed module

\section{Discussion}

Teaching and learning process for English for Biology requires more adaptable teaching materials in its approach to determine the module's effectiveness. Innovation and a variety of approaches are needed to make teaching and learning can deal with the complexity of the nature of students in English proficiency. The lecturer's role is crucial in determining what and how the subject is delivered considering all aspects of both material and strategy.

The Research and Development must go through four steps of activities, the Planning, Designing, Validating, and Field Testing. The module has been validated and tested for both the practicality and effectiveness and assumed it has the expected quality as the teaching material for the English for Biology subject. A product is good when it has been validated, and tested for its practicality and effectiveness [9]. In each step evaluation is part of the processes, the validation and tests are the most important as the output of the module is going to be developed at this stage. That's why the validation indicators are designed accurately in order to have a good result.

The validation tests for the content and design shows a good sign for the module to be used as the teaching material, there are some parts of it need to be revised. From the research point of view the use of students and lecturers should not be the only source of information or responses about the module. Using students as the respondents give the researcher the doubt about their dedication and time to answer the questionnaires. On top of these two fairly doubting situation, the students should not become the representative of the students as they do not have a standardized level of English (Figure 2). This figure just to make an example of the variability of the score based on the examination run by the government alone. Variability score of their SKHUN suggested that they are not eligible to assess the module [10]. Half way 
of the process, between the pre and post-test more than half of the students left the activity with the statement that they just cannot do the test. There were only 46 of them who declared worthy to do the test. It was assumed that a more confident and representative students, more eligible candidates, will make a difference conclusion to the result.

The other problem about the sample is that the lecturers do not have enough time to recall what the students have learnt in the past. As English is categorized as a skill, it was much better when the sample consists of students who have been taught and chosen to fill the questionnaires and the pre and post-test. Considering their condition the total sample was not the best choice, purposive sampling is recommended. The material for the test was only part of the module and this may result in insufficient data to claim about the whole module. The module consists of six topic, they are grammar/parts of speech (verb, noun, and adjective only), affixes, types of sentence, active and passive voices, paragraph, and reading comprehension.

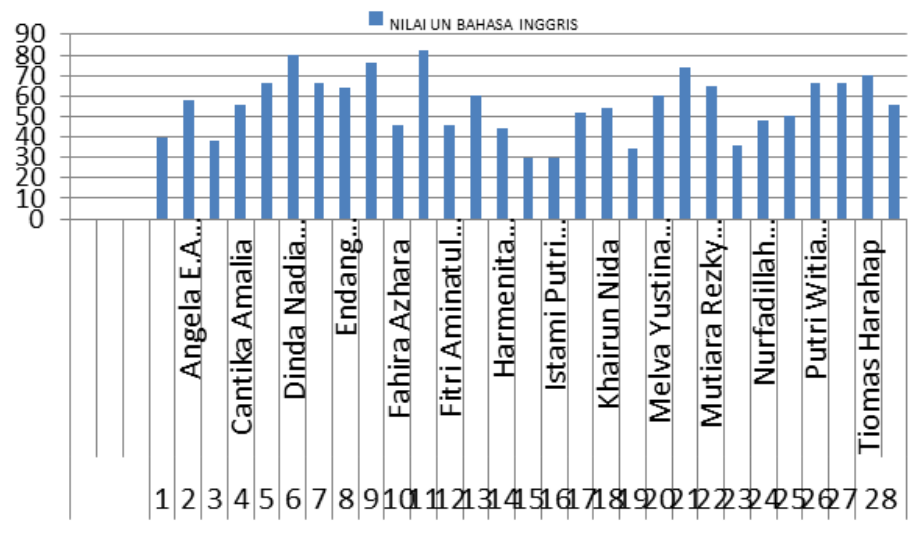

Fig 2. Student's Score based on the SKHUN

The test did not include the material of affixes, active and passive voices, types of sentence and paragraph. The test about the later material is practically time consuming and is better to have different time allocation. The result from the test did not cover all about the module and it has not touch the core of the syllabus.

The result also dictates us about the fact that teaching skills must be done in a regular basis. The teaching material for the Parts of speech has the allocation of two meetings and the next topic is the affixes. The students were doing the assignment for this topic that is the routine assignments or Tugas Rutin, and they have to submit the task for four weeks in a row. The identification process of noun, verb and adjective in sentences together with the effort to build up vocabulary while doing the exercise seemed to have not really helping the students with low confident in grammar. A limited vocabulary and time are factors which probably responsible for the unsuccessful result. It was also found that the students who were good in the pre-test were exactly the same students who were doing well in the post-test. Statistically, the module has shown the significant implication of the module on the student's achievement in the test. The research also revealed that the module did not really depict the improvement in personal achievement. The vocabulary were only written as a home work and submitted on time for four weeks but the tests shows similar trend that students have a great deal of problem. The assumption can be clearly stated that the module is practically helpful and useful but time limitation was hindering the goal. 
Although attitude is not part of the research but it was found that most of students were not ready in term of content comprehension. The research also found that some students were not confident about the terminology and words and process used in the area of Biology. The question about when do they "learn to comprehend" is another issue to deal with. Some of them were not very sure about their knowledge in Biology on top of their weakness in English's grammar and vocabulary.

The rest of the topics such as paragraph and reading comprehension are related to the higher level cognitive skills. Students in this research have very little skill to study and practice the topic of paragraphing and reading. Research has identified a number of cognitive processes involved in reading comprehension [11,12], and a research focus on the shared knowledge required to complete reading has to be proposed to accompany this research.

In general, the topic of paragraph is one of the most difficult tasks to teach. Lack of knowledge about topic, sentence, words, and a paragraph itself has made the learning activity quite slow and uncertain. Students do not have knowledge about how a paragraph is building up. The information about a good paragraph that support or develop a single controlling idea was new for most of them. They are also not aware about that a single controlling idea is called the topic sentence. Activity to identify the topic sentence in the paragraph was wellknown to be the longest time.

The module does not come alone, it has other strategies such as puzzle and games attach to it. There are several reasons for doing this. First of all, young learners have endless energy but all schedule for every group of students, for this subject are mostly after $1.00 \mathrm{pm}$. Time that is not really promising. Secondly, the classes are considered big, and it is difficult to organize a group of 20-30 students. Another reason is that they do not have many words. Their vocabulary is not rich even in Bahasa Indonesia. It is unlikely we succeed in explaining them something difficult in English, which is why playing language games is the best way to work with students.

The failure to successfully learning the paragraph leads to have more difficult in writing. The module does not include the activity of writing and it is believed that students must have a specific course or time to be able to study it. This needs attention as writing is a critical part of the scientific process. It is often taught secondarily to scientific concepts and becomes an afterthought to students. Although it is also believed that scientific writing is often difficult and arduous task for many students [13].

The overall findings indicate that the students with high level of confident in English, grammar and vocabulary, have more ability to study the rest of the module. Factors such as lecturer, dictionary, and other strategy such as games and puzzle, playing cards, and the project of mini dictionary, seemed have no real impact on their achievement in the tests. The real problem is the lack of knowledge in biology and low confident in English proficiency of most of the students. The real and important is to suggest the University to adjust this demand with having more credits, SKS, if the quality of student's English proficiency is the real problem. Lecturers are also the important part of the process and to put more resources to enhance their capability to deal with the students' various level of English proficiency. 


\section{References}

[1] Biology Department, Syllabus of Bahasa Inggris Biology subject. University Negeri Medan (2019).

[2] Bischoff, P. J., Hatch, D. D., \& Watford, L. J. The state of readiness of initial level preservice middle grades science and mathematics teachers and its implications on teacher education programs. School Science and Mathematics, Bowling Green, 99(7), 394-399 (1999).

[3] Hudon, P. Learning to teach scinece using English as the medium of instruction. Eurasia Journal of mathematics, Science and technology Education 5(2) (2009).

[4] Teachers of English to Speakers of Other Languages. ESL Standards for PreK-12 Students. Alexandria, VA: Author (1997).

[5] Bell, D. Help! I've been asked to teach a class on ESP! IATEFL Issues 169. (2002).

[6] Porcaro, J. W. Teaching English for Science and Technology: An Approach for Reading with Engineering English. English Teaching Forum, No.2, pp. $32-38$ (2013).

[7] Sainani, K., Elliott, C., and Harwell, D. Active vs. passive voice in scientific writing. American Chemical Society. Available from:

https://www.acs.org/content/dam/acsorg/events/professional development /Slides/2015-04-09-active-passive.pdf [Accessed 20th October 2019]

[8] Baer, J. \& Grath, D. The Reading Literacy of U.S. Fourth-Grade Students in an International Context. U. S. Department of Education NCES 2008-017, (2007).

[9] Neeven, N. Prototyping to Reach Product Quality. in Akker, et.al. (2009) (Eds), Design Approaches and Tools in Education and Training. Netherlands: Springer Science+ Business Media. Dordrecht (1999).

[10] Collection of Biology Students' SKHUN scores. Universitas Negeri Medan (2019).

[11] Myers, J. L., \& O’Brien, E. J. Accessing the discourse representation during reading. Discourse Processes, 26, 131-157 (1998).

[12] Allen, L. K., Snow, E. L., Crossley, S. A., and Jackson, G. T. et Mc. Namara. D. S. Reading comprehension components and their relation to writing. L' Anněe psychologiue 2014/4(Vol. 114), Pages 663 - 691 (2014).

[13] Hannon, B., \& Daneman, M. A new tool for measuring and understanding the individual differences in the component processes of reading comprehension. Journal of Educational Psychology, 93, 103-128 (2001). 